OPEN ACCESS

Edited by:

Utpal S. Bhalala,

Baylor College of Medicine,

United States

Reviewed by:

Dimpna Calila Albert-Brotons, King Faisal Specialist Hospital \&

Research Center, Saudi Arabia Pooja Nawathe,

Cedars Sinai Medical Center, United States

*Correspondence:

Nailya I. Kubysheva aibolit70@mail.ru

TORCID:

Alina V. Gordina

orcid.org/0000-0002-5966-6419

Ksenia A. Egoshina

orcid.org/0000-0002-1236-6638

Tatyana I. Eliseeva

orcid.org/0000-0002-1769-3670

Nadezhda G. Vinogradova orcid.org/0000-0002-3391-7937

Dmitry Yu. Ovsyannikov orcid.org/0000-0003-3452-8666

Elena V. Tush orcid.org/0000-0002-5961-9794

Andrey V. Prakhov orcid.org/0000-0002-7978-3831

Mojisola I. Daniel-Abu orcid.org/0000-0003-1579-3659

Olga V. Khaletskaya orcid.org/0000-0002-8531-3174

Nailya I. Kubysheva orcid.org/0000-0002-5582-5814

Specialty section:

This article was submitted to

Pediatric Cardiology,

a section of the journal

Frontiers in Pediatrics

Received: 24 March 2020

Accepted: 06 August 2020

Published: 16 September 2020

Citation:

Gordina AV, Egoshina KA, Eliseeva TI, Vinogradova NG, Ovsyannikov DY, Tush EV, Prakhov AV, Daniel-Abu MI, Khaletskaya OV and Kubysheva NI (2020) The Relationship Between Bronchial Patency and Parameters of ECG Supraventricular Component in Children With Bronchial Asthma. Front. Pediatr. 8:576 doi: 10.3389/fped.2020.00576

\section{The Relationship Between Bronchial Patency and Parameters of ECG Supraventricular Component in Children With Bronchial Asthma}

\author{
Alina V. Gordina ${ }^{1 \dagger}$, Ksenia A. Egoshina ${ }^{1 \dagger}$, Tatyana I. Eliseeva ${ }^{1 \dagger}$, \\ Nadezhda G. Vinogradova ${ }^{1,2 t}$, Dmitry Yu. Ovsyannikov ${ }^{3 t}$, Elena V. Tush ${ }^{1 \dagger}$, \\ Andrey V. Prakhov ${ }^{1 \dagger}$, Mojisola I. Daniel-Abu ${ }^{3 \dagger}$, Olga V. Khaletskaya ${ }^{1 \dagger}$ and \\ Nailya I. Kubysheva ${ }^{4 * t}$ \\ ${ }^{1}$ Privolzhsky Research Medical University, Nizhny Novgorod, Russia, ${ }^{2}$ City Clinical Hospital No. 38, Nizhny Novgorod, Russia, \\ ${ }^{3}$ Department of Pediatrics, Peoples' Friendship University of Russia (RUDN University), Moscow, Russia, ${ }^{4}$ Research \\ Laboratory "Clinical Linguistics", Kazan Federal University, Kazan, Russia
}

Background: Uncontrolled asthma (BA) can be complicated by cardiac conduction disturbances and arrhythmias. It is typical mainly for adult asthmatics patients. In asthmatics children the effect of bronchoconstriction on cardiac conduction, including the supraventricular component of the ECG, is currently under discussion. The objective of the research is to analyze ECG parameters of the atrial complex and atrioventricular conduction and to assess their relationship with spirometric indicators in children with BA.

Methods: Hundred three patients with BA from the age of 6-17 years were examined. The spirometric parameters were evaluated, including the Tiffeneau index (TI): FEV1/FVC (\%), according to the level of which the patient groups were distinguished. Group 1 (G1): with TI more than 85\%, ( $(n=15)$; Group 2 (G2): with TI from 85 to 75\%, $(n=40)$; Group 3 (G3): with $\mathrm{TI}<75 \%$, $(n=48)$. The ECG parameters that characterize supraventricular conduction, including the $P Q$ interval (sec) and the $S P Q$ segment (sec), were analyzed. We had calculated relative $P Q(r P Q)$ by the formula $r P Q=P Q / P Q m e d$, where $P Q$ is the patient's $P Q, P Q m e d$ are the median $P Q$ values of healthy children of age selected.

Results: The duration of the PQ in groups G1 and G2 was $0.13(0.11 ; 0.14)$ s; and $0.13(0.12 ; 0.14) \mathrm{s}$, respectively, which is statistically significantly less than in patients of groups G3-0.14 $(0.13 ; 0.15] \mathrm{s}, p=0.01$. The duration of the SPQ segment in children of groups G1 and G2 was also generally shorter than in patients of groups G3, and amounted, respectively, to $0.05(0.04 ; 0.06) \mathrm{s}, 0.04(0.04 ; 0.05) \mathrm{s}$, and $0.06(0.04 ; 0.07)$ $\mathrm{s}, p=0.02$. The rPQ increased progressively as $\mathrm{Tl}$ decreased and amounted in $\mathrm{G} 1$ to $92.9(85.7 ; 106.3) \%$, in G2 100.0 (92.9; 103.0) \%, and in G3 $104(100.0 ; 107.7) \%, p=$ 0.009. A statistically significant negative correlation between IT and PQ- $r=-0.23, p=$ 0.02; with $\mathrm{SPQ}-r=-0.20, p=0.045$; and with $r P Q-r=-0.25, p=0.01$ was revealed.

Conclusion: A decrease in $\mathrm{TI}$ in asthmatics children is associated with a prolongation of the PQ. This may indicate a slowdown in supraventricular conduction in patients with uncontrolled asthma and, thus, be considered as a risk for the formation of subsequent supraventricular arrhythmias.

Keywords: bronchial patency, ECG, supraventricular component, bronchial asthma, children 


\section{INTRODUCTION}

Bronchial asthma (BA) is a chronic inflammatory disease of the respiratory tract, the leading clinical manifestations of which are reversible bronchoconstriction and bronchial hyperreactivity (1-3). The goal of BA therapy at this stage is achieving control over symptoms and risk factors of exacerbation of the disease (4-6). However, the course of BA can be complicated by various comorbidities, which have a negative influence on the achievement of control (7-12).

That said, insufficient control of BA, in turn, can cause the formation of various pathological conditions. For example, there are studies showing the risk of cardiac arrhythmias and conduction disorders in patients with uncontrolled BA due to functional changes or pathological remodeling of the myocardium (13-16). Atrial remodeling, which is the pathomorphological basis of serious supraventricular cardiac arrhythmias, has a more rapid progression with poor BA control and is formed as a result of excessive stretching of the atrial wall, as well as other adverse factors (17).

The connection between BA and supraventricular arrhythmias, including atrial fibrillation (AF), was noted in studies by Warnier et al. (18), Goudis et al. (19), and Cepelis et al. (20). Available data indicate that in the adult population, cardiac arrhythmias are significantly more common in patients with BA than in those without it $(13,18,21,22)$. The results of a Norwegian population study HUNT study, demonstrate that the risks of supraventricular arrhythmias and $\mathrm{AF}$ are increased in patients with an uncontrolled BA (20).

Despite the fact that AF is diagnosed primarily in adult patients with $\mathrm{BA}$, other supraventricular arrhythmias are described in patients with childhood BA $(18,23-25)$. At the same time, there are a number of studies demonstrating the development of atrial remodeling and changes in the electrophysiological properties of the atria of children with BA $(23,26)$. Probably, one of the reasons for the significant impairment of the electrophysiological properties of the atria may be impairments of bronchial patency. Thus, the prerequisites for the development of severe supraventricular arrhythmias in patients with BA may be formed in childhood. Therefore, identifying markers of the risk of supraventricular arrhythmias in children with BA will help predict their development and prevent cardiac complications of asthma, particularly in its uncontrolled form, in both children and adults.

Consequently, it should be noted that in the study of Çiftel et al. it was found that patients with BA are characterized by disorders of electrophysiological properties of the right atrium, which consist of an increase in the intra-atrial and interatrial conduction time. This, according to the authors, can be considered as a predictor of supraventricular arrhythmias in patients with BA, the risk of which increases as the severity and duration of uncontrolled asthma increases (26).

Electrocardiography (ECG) is the universal screening method for assessing the state of the atrial myocardium and the conducting system of the heart. According to German et al. ECG analysis can make a significant input to the assessment of the risk of formation of supraventricular rhythm and conduction disorders. Therefore, the analysis of the atrial component of the ECG, and atrioventricular conduction in patients with $\mathrm{BA}$ is an important component of the management of these patients, especially in pediatric practice (27). Consequently, the study of the characteristics of the ECG and its supraventricular component in children with BA is relevant.

Considering the available data on the reduced rate of atrial conduction in patients with an insufficient level of asthma control, it is important also to study the relationship between ECG parameters that characterize the atrial complex and atrioventricular conduction, and spirometric parameters that reflect the severity of bronchial obstruction, an important component in the formation of clinical manifestations of asthma $(28,29)$. However, to date, the evaluation of the ECG atrial component and atrioventricular conduction in patients with childhood BA remains insufficiently researched. Studies dedicated to the evaluation of the supraventricular component of ECG in relation to the state of bronchial patency in children with BA, which would allow us to identify predictors of myocardial remodeling and supraventricular rhythm disorders in children and to predict the development of these complications of BA, were not found in the literature.

The purpose of this study, therefore, is to analyze the electrocardiographic parameters of the atrial complex and atrioventricular conduction and evaluate their relationship with spirometric indicators in children with bronchial asthma.

\section{MATERIALS AND METHODS}

\section{Formation of a Cohort of Patients}

The study was carried out in accordance with the Helsinki Declaration adopted in June 1964 (Helsinki, Finland), and revised in October 2000 (Edinburgh, Scotland). The study was approved by the Ethics Committee of the Privolzhsky Research Medical University, Protocol No. 13 of 10.10.2016. Informed consent was obtained from patients aged 15-17 years, and from the parents of patients under the age of 15 years, in accordance with Federal law No. 323 of 21.11.2011 "On the basics of health protection of citizens in the Russian Federation."

Hundred three children aged 6-17 years were examined, of which, boys made up $67.6 \%$ (71/103), and girls-32.4\% (32/103), These patients were treated for bronchial asthma in the Nizhny Novgorod City Children's Clinical Hospital No. 1.

The inclusion criteria were a diagnosis of $\mathrm{BA}$, made in accordance with current international and national consensus documents, and the presence of a sinus rhythm based on the results of an ECG analysis $(3,30)$. The exclusion criteria were: saturation below $98 \%$, the presence of acute infectious diseases and fever (31), diabetes, autoimmune disorders, primary immunodeficiency and cancer, oral glucocorticoids.

BA treatment was carried out in accordance with existing consensus documents, taking modern therapeutic strategies into account $(1,3,6,12)$.

\section{Objective Measurements}

In addition to general clinical and allergy examinations, all patients underwent spirometric and electrocardiographic tests, as 
well as the measurement of the main anthropometric indicators. Saturation was evaluated using the pulse oximetry method (medical pulse oximeter "Armed" YX302, China). Spirometric tests were performed using the MasterScreen Pneumo spirometer (Jaeger, Germany), in accordance with existing international recommendations (32). Also assessed were the forced vital capacity (FVC), forced expiratory volume per second $\left(\mathrm{FEV}_{1}\right)$, and maximal expiratory flow at $25 \%$ of the flow-volume curve $\left(\mathrm{MEF}_{25}\right)$; data were recorded in absolute values and in relative units, i.e., percentages of reference values (\% predictedhereafter $\%$ pred), subject to gender, age and anthropometric indices of the child. Also, the Tiffeneau index $\left(\mathrm{FEV}_{1} / \mathrm{FVC}\right)^{*} 100 \%$ was evaluated $(3,32-34)$.

The Tiffeneau Index (TI) was used as a marker for bronchial patency. A TI value $>85 \%(3,33)$, indicated that bronchial patency was unimpaired or slightly impaired, with TI values $<85 \%$ but more than $75 \%$, moderate bronchial obstruction was considered, and with TI values $<75 \%$, patients were considered to have serious impairment of bronchial patency $(3,33)$. ECG recording was performed on a multichannel Cardiofax $S$ electrocardiograph (NihonKonden, Japan) at a paper speed of $50 \mathrm{~mm} / \mathrm{s}$. The atrial complex of the electrocardiogram and atrioventricular conduction were analyzed based on the height of the $P$-wave $(\mathrm{mm})$, the total duration of $P$-wave $(\mathrm{sec})$, the duration of PQ interval ( $\mathrm{sec}$ ), the duration of the segment sPQ (sec) in the II standard lead. The value of sPQ (sec) was determined as the difference between PQ (sec) and duration of $P$-wave (sec). Also evaluated were the heart rate (HR, beats per minute), and the duration of the RR interval ( $\mathrm{sec}$ ). The relative value of interval PQ (rPQ) was also calculated, using the formula: $r P Q=P Q / P Q m e d$, where $P Q$ is the duration of $P Q$ interval of the patient, and PQmed is the median duration of PQ interval, typical for children of this age and gender (32). Also, the fraction of the PQ interval $(\mathrm{sec})$ in the total duration of the cardiac cycle $(\mathrm{R}-\mathrm{R}, \mathrm{sec})$ was calculated-PQ/RR $\times 100 \%$.

\section{Statistical Analysis}

Since this was a pilot study, the sample size was not calculated. Statistical analysis was done using the Statgraphics Centurion V. 16.1.17 software package. The data is presented in the form of $\mathrm{Me}[\mathrm{A} 1 ; \mathrm{A} 2]$, where $\mathrm{Me}$ is the median, $[\mathrm{A} 1 ; \mathrm{A} 2]$ are the lower and upper bounds of the $95 \%$ confidence interval.

For quantitative features, standardized skewness and standardized kurtosis were calculated to determine the normality of the sample. Quantitative data for which the calculated values of standardized asymmetry and standardized kurtosis were outside the range of -2 to +2 were characterized as different from normal values. Samples of indicators such as age (years), FVC (liters), FVC\% (\%pred), heart rate (BPM), ampP (mm), $P$ (sec), rPQ (\%), sPQ (sec), rHR (\%), RR (sec) were normal.

Differences between two independent samples with normal distribution were determined using the Student $t$-test and between three or more independent samples using the $F$ test (ANOVA variance analysis). The differences between two independent samples different from normal ones were calculated using the non-parametric Wilcoxon-Mann-Whitney test (W criterion, comparing the medians of two samples); between three or more independent samples-using the Kruskal-Wallis test (KWT, comparing the medians of several samples). The relationship between independent samples was evaluated using the Spearman correlation coefficient $r$. The level of statistical significance was taken as $p<0.05$.

\section{RESEARCH RESULTS}

\section{Clinical Characteristics of Patients}

The study included children and adolescents from 6 to 17 years of age, with a median age of $11.0(6.0 ; 17.0)$ years. Boys and girls were comparable in age and anthropometric indicators, including height, body weight, and BMI, Table 1.

Spirometry parameters measured in absolute terms and in relative units (\% pred) in this sample had no statistically significant gender differences, with the exception of FVC (liters), which was higher for boys than for girls $(p=0.04)$. Indicators characterizing the ECG atrial complex and atrioventricular conduction, including the height $(\mathrm{mm})$ and duration $(\mathrm{sec})$ of the $P$-wave, the duration of the PQ interval (sec), and the sPQ segment (sec) in boys and girls in the study sample were comparable. The median heart rate for girls was higher than for boys, $p=0.04$. Accordingly, the rHR (\%) in the girls' group was higher than in the boys' group $(p=0.03)$. For the same reason, the duration of RR (sec) in girls was less than in boys, $p=0.03$. Given, however, that most of the studied parameters of both the ECG and spirometry had no gender differences in the available sample, further analysis of indicators was carried out in the total sample of patients without regard to their gender.

We evaluated the relationship of the main parameters characterizing the ECG atrial component, with the age of the patients with BA who were examined, Table 2. It was found that the duration of the intervals PQ ( $\mathrm{sec}$ ) and RR ( $\mathrm{sec}$ ) have a statistically significant relationship with the age of the child, $p=0.008$ and $p=0.0002$, respectively. This suggests that considering these parameters as a single sample in a common cohort of children of different ages would be incorrect. Because of this, we have introduced additional relative values to qualify the PQ (sec) and RR (sec) intervals, $-r P Q$, and $r R R$, respectively. These parameters were normalized to the median values after accounting for the age and height of patients (32). Relative parameters are equations: $r P Q=P Q / P Q m e d$, where $P Q$ is the patient's $P Q$ values, $P Q$ med is the median $P Q$-values typical of children of this age; and $r R R=R R / R R m e d$, where $\mathrm{RR}$ is the patient's RR values, RRmed is the median $R R$ values typical of children of this age.

\section{Indicators of ECG Atrial Component and Supraventricular Conduction in Children With Different Degrees Severity of Bronchoconstriction}

When considering atrial conduction parameters, it was found that children who had the most pronounced manifestations of bronchoconstriction (Group 3, Tiffeneau index <75\%) had a statistically significant lengthening of the PQ interval (sec), $p=$ 0.01 ; an increase in the rPQ coefficient (\%), $p=0.009$; and an extension of the sPQ segment (sec), $p=0.02$, compared with patients in Group 1 (Tiffeneau index more than 85\%) and Group 
TABLE 1 | Clinical and functional characteristics of the examined BA patients.

\begin{tabular}{|c|c|c|c|}
\hline Parameters & Boys & Girls & Statistics \\
\hline Number of patients & 71 & 32 & \\
\hline Age, years & $\begin{array}{c}11.0 \\
(10.0 ; 12.0)\end{array}$ & $\begin{array}{c}11.0 \\
(9.0 ; 14.0)\end{array}$ & $\begin{aligned} t & =0.003 ; p=1.0 \\
W & =1138.5 ; p=0.99\end{aligned}$ \\
\hline Height, cm & $\begin{array}{c}150.0 \\
(141.0 ; 163.5)\end{array}$ & $\begin{array}{c}151.0 \\
(143.0 ; 160.0)\end{array}$ & $W=998.5 ; p=0.33$ \\
\hline Weight, kg & $\begin{array}{c}43.5 \\
(35.9 ; 54.3)\end{array}$ & $\begin{array}{c}41.5 \\
(29.5 ; 52.0)\end{array}$ & $W=974.0 ; p=0.25$ \\
\hline $\mathrm{BMI}, \mathrm{kg} / \mathrm{m}^{2}$ & $\begin{array}{c}18.5 \\
(17.0 ; 20.0)\end{array}$ & $\begin{array}{c}18.5 \\
(15.9 ; 20.1)\end{array}$ & $W=998.5 ; p=0.33$ \\
\hline FVC, I & $\begin{array}{c}3.24 \\
(2.89 ; 3.90)\end{array}$ & $\begin{array}{c}2.94 \\
(2.57 ; 3.76)\end{array}$ & $\begin{array}{c}t=2.12 ; p=0.04 \\
W=893.5 ; p=0.08\end{array}$ \\
\hline FVC, \%pred & $\begin{array}{c}113.2 \\
(108.1 ; 117.0)\end{array}$ & $\begin{array}{c}113.3 \\
(104.7 ; 126.0)\end{array}$ & $\begin{array}{c}t=-0.33 ; p=0.74 \\
W=1185.0 ; p=0.73\end{array}$ \\
\hline $\mathrm{FEV}_{1}, \mathrm{I}$ & $\begin{array}{c}2.25 \\
(1.96 ; 2.82)\end{array}$ & $\begin{array}{c}2.23 \\
(1.62 ; 2.83)\end{array}$ & $W=961.5 ; p=0.21$ \\
\hline $\mathrm{FEV}_{1}, \%$ pred & $\begin{array}{c}101.1 \\
(97.5 ; 104.6)\end{array}$ & $\begin{array}{c}100.9 \\
(93.0 ; 111.4)\end{array}$ & $W=1155.0 ; p=0.90$ \\
\hline Tiffeneau index, \% & $\begin{array}{c}73.2 \\
(70.7 ; 77.1)\end{array}$ & $\begin{array}{c}76.1 \\
(72.0 ; 81.6)\end{array}$ & $W=904.0 ; p=0.07$ \\
\hline $\mathrm{MEF}_{25}, \mathrm{l} / \mathrm{s}$ & $\begin{array}{c}0.86 \\
(0.67 ; 1.02)\end{array}$ & $\begin{array}{c}0.82 \\
(0.70 ; 1.25)\end{array}$ & $W=1131.0 ; p=0.83$ \\
\hline $\mathrm{MEF}_{25}, \%$ pred & $\begin{array}{c}48.3 \\
(43.5 ; 55.9)\end{array}$ & $\begin{array}{c}51.6 \\
(41.0 ; 74.9)\end{array}$ & $W=1212.0 ; p=0.42$ \\
\hline $\mathrm{HR}, \mathrm{BPM}$ & $\begin{array}{c}75.0 \\
(72.0 ; 77.3)\end{array}$ & $\begin{array}{c}80.0 \\
(74.0 ; 88.0)\end{array}$ & $\begin{array}{c}t=-2.12 ; p=0.04 \\
W=1438.5 ; p=0.03\end{array}$ \\
\hline $\mathrm{rHR}, \%$ & $\begin{array}{c}93.2 \\
(90.1 ; 95.8)\end{array}$ & $\begin{array}{c}97.7 \\
(92.5 ; 102.8)\end{array}$ & $\begin{array}{c}t=-2.23 ; p=0.03 \\
W=1447.5 ; p=0.03\end{array}$ \\
\hline RR, sec & $\begin{array}{c}0.80 \\
(0.78 ; 0.83)\end{array}$ & $\begin{array}{c}0.75 \\
(0.68 ; 0.81)\end{array}$ & $\begin{array}{c}t=4.74 ; p=0.03 \\
W=833.5 ; p=0.03\end{array}$ \\
\hline$P$, sec & $\begin{array}{c}0.08 \\
(0.08 ; 0.09)\end{array}$ & $\begin{array}{c}0.08 \\
(0.06 ; 0.09)\end{array}$ & $\begin{aligned} t & =0.83 ; p=0.41 \\
W & =1005.0 ; p=0.34\end{aligned}$ \\
\hline amp P, mm & $\begin{array}{c}1.5 \\
(1.0 ; 1.5)\end{array}$ & $\begin{array}{c}1.5 \\
(1.0 ; 2.0)\end{array}$ & $\begin{array}{c}t=-1.49 ; p=0.14 \\
W=1314.0 ; p=0.18\end{array}$ \\
\hline$P Q$, sec & $\begin{array}{c}0.13 \\
(0.13 ; 0.14)\end{array}$ & $\begin{array}{c}0.13 \\
(0.12 ; 0.14)\end{array}$ & $W=935.0 ; p=0.14$ \\
\hline$r P Q, \%$ & $\begin{array}{c}100.0 \\
(100.0 ; 107.1)\end{array}$ & $\begin{array}{c}92.9 \\
(92.3 ; 100.0)\end{array}$ & $\begin{array}{c}t=1.35 ; p=0.18 \\
W=892.5 ; p=0.08\end{array}$ \\
\hline$S P Q, s e c$ & $\begin{array}{c}0.05 \\
(0.04 ; 0.06)\end{array}$ & $\begin{array}{c}0.05 \\
(0.04 ; 0.06)\end{array}$ & $\begin{aligned} t & =0.22 ; p=0.82 \\
W & =1142.5 ; p=0.97\end{aligned}$ \\
\hline
\end{tabular}

BMI, kg/m2-body mass index; FVC, l-forced vital capacity; FVC, \%pred-percentage of predicted FVC; FEV 1 , I-forced expiratory volume in first second; FEV 1 , \%pred-percentage of predicted $\mathrm{FEV}_{1} ; \mathrm{MEF}_{25}$, l/s-maximal expiratory flow rate at $25 \%$ of flow-volume loop; $M E F_{25}$, \%pred-percent of predicted MEF $25 ; H R, B P M$-heart rate; $P$, sec-duration of $P$ wave; amp $P, m m$ - amplitude of $P$ wave; $P Q$, sec-duration of $P Q$ interval; $r P Q=P Q / P Q$ med $\times 100 \%$; $s P Q$, sec-duration of the $P Q$ segment; $r H R=H R / H R$ med $\times 100 \%$; $R R$, sec-duration of RR interval.

2 (Tiffeneau index from 75 to $85 \%$ ), Table 3, Figure 1. At the same time, no intergroup differences in the values of $P(\mathrm{sec}), \mathrm{RR}$ (sec), rRR (\%), and ampP (mm) were established.

When evaluating the relationship between ECG and spirometric parameters, we established a statistically significant positive correlation between the duration of the $P$-wave $(\mathrm{sec})$ and heart rate (BPM) with such absolute indicators of external respiration as FVC (1), FEV 1 (1), Table 4. A similar relationship was also established between the duration of the PQ interval (sec) and the value of FVC (1). This seems to reflect the influence of
TABLE 2 | Relationship between atrial conduction parameters and age (years) of patients, $n=103$.

\begin{tabular}{lc}
\hline ECG parameter & $\boldsymbol{R , p}$ \\
\hline $\mathrm{P}, \mathrm{sec}$ & $R=0.07 ; p=0.50$ \\
$\mathrm{PQ}, \mathrm{sec}$ & $R=0.26 ; p=0.0078$ \\
$\mathrm{SPQ}, \mathrm{sec}$ & $R=0.14 ; p=0.16$ \\
$\mathrm{ampP}, \mathrm{mm}$ & $R=0.01 ; p=0.92$ \\
$\mathrm{RR}, \mathrm{sec}$ & $R=0.35 ; p=0.03$ \\
\hline
\end{tabular}

$P$, sec-duration of $P$ wave; $P Q$, sec-duration of $P Q$ interval; $s P Q$, sec-length of $P Q$ segment; amp $P, m m$-amplitude of $P$ wave; $R R$, sec-duration of $R R$ interval; $R$, correlation coefficient; $p$, level of statistical significance.

TABLE 3 | ECG parameters in children with different degrees of severity of bronchoconstriction.

\begin{tabular}{|c|c|c|c|c|}
\hline $\begin{array}{l}\text { ECG } \\
\text { parameters }\end{array}$ & Group 1 & Group 2 & Group 3 & Statistics \\
\hline $\begin{array}{l}\text { Number of } \\
\text { patients }\end{array}$ & 15 & 40 & 48 & \\
\hline$P$, sec & $\begin{array}{c}0.08 \\
(0.06 ; 0.08)\end{array}$ & $\begin{array}{c}0.09 \\
(0.08 ; 0.10)\end{array}$ & $\begin{array}{c}0.08 \\
(0.07 ; 0.08)\end{array}$ & $\begin{array}{c}F=1.91 ; p=0.15 \\
\mathrm{KWT}=4.38 ; p=0.11\end{array}$ \\
\hline$P Q$, sec & $\begin{array}{c}0.13 \\
(0.11 ; 0.14)\end{array}$ & $\begin{array}{c}0.13 \\
(0.12 ; 0.14)\end{array}$ & $\begin{array}{c}0.14 \\
(0.13 ; 0.15)\end{array}$ & $\begin{array}{c}F=5.66 ; p=0.005 \\
\mathrm{KWT}=9.07 ; p=0.01\end{array}$ \\
\hline rPQ, \% & $\begin{array}{c}92.9 \\
(85.7 ; 106.3)\end{array}$ & $\begin{array}{c}100.0 \\
(92.9 ; 103.0)\end{array}$ & $\begin{array}{c}104.0 \\
(100.0 ; 107.7)\end{array}$ & $\begin{array}{c}F=5.87 ; p=0.004 \\
\mathrm{KWT}=9.32 ; p=0.009\end{array}$ \\
\hline sPQ, sec & $\begin{array}{c}0.05 \\
(0.04 ; 0.06)\end{array}$ & $\begin{array}{c}0.04 \\
(0.04 ; 0.05)\end{array}$ & $\begin{array}{c}0.06 \\
(0.04 ; 0.07)\end{array}$ & $\begin{array}{l}F=5.10 ; p=0.008 \\
\mathrm{KWT}=8.05 ; p=0.02\end{array}$ \\
\hline $\mathrm{RR}$, sec & $\begin{array}{c}0.76 \\
(0.69 ; 0.87)\end{array}$ & $\begin{array}{c}0.77 \\
(0.72 ; 0.81)\end{array}$ & $\begin{array}{c}0.81 \\
(0.75 ; 0.88)\end{array}$ & $\begin{array}{c}F=2.73 ; p=0.07 \\
\mathrm{KWT}=3.85 ; p=0.15\end{array}$ \\
\hline HR, BPM & $\begin{array}{c}79.0 \\
(69.0 ; 87.1)\end{array}$ & $\begin{array}{c}78.0 \\
(74.0 ; 83.7)\end{array}$ & $\begin{array}{c}74.5 \\
(68.0 ; 80.0)\end{array}$ & $\begin{array}{c}F=1.97 ; p=0.14 \\
\mathrm{KWT}=3.85 ; p=0.15\end{array}$ \\
\hline rHR, \% & $\begin{array}{c}95.8 \\
(87.5 ; 98.6)\end{array}$ & $\begin{array}{c}94.7 \\
(92.1 ; 102.7)\end{array}$ & $\begin{array}{c}92.5 \\
(83.8 ; 99.2)\end{array}$ & $\begin{array}{c}F=1.31 ; p=0.28 \\
\mathrm{KWT}=2.32 ; p=0.31\end{array}$ \\
\hline ampP, mm & $\begin{array}{c}1.5 \\
(1.0 ; 2.0)\end{array}$ & $\begin{array}{c}1.5 \\
(1.0 ; 2.0)\end{array}$ & $\begin{array}{c}1.3 \\
(1.0 ; 1.8)\end{array}$ & $\begin{array}{c}F=0.61 ; p=0.55 \\
\mathrm{KWT}=1.01 ; p=0.60\end{array}$ \\
\hline
\end{tabular}

Group 1, Patients with TI > 85\%; Group 2, Patients with 75\% < TI <85\%; Group 3, Patients with $\mathrm{TI}<75 \%$. The data is presented in the form of Me [A1; A2], where Me is the median, [A1; A2] is the lower and upper limits of the $95 \%$ confidence interval. $P$, sec-duration of $P$ wave; $P Q$, sec-duration of $P Q$ interval; $r P Q=P Q / P Q$ med $\times 100 \%$; $s P Q$, sec-length of $P Q$ segment; $R R$, sec-duration of RR interval; HR, BPM-heart rate in beats per minute; amp $P, m m$-amplitude of $P$ wave.

age and anthropometric parameters of children and adolescents on some ECG indicators, as well as on the absolute values of spirometric parameters.

In this study, a statistically significant negative correlation between the duration of the PQ interval (sec) and sPQ (sec), and relative spirometrics parameters, that characterize bronchial patency, including TI (\%) and $\mathrm{FEV}_{1}$ (\%pred) was established. A statistically significant negative correlation was also established between rPQ (\%) and spirometry indicators such as $\mathrm{MEF}_{25}$ (\%pred), TI (\%), $\mathrm{FEV}_{1}$ (\%pred), and $\mathrm{MEF}_{25}$ (1/s). The results obtained suggest that the worsening of bronchial obstruction in children with BA may be accompanied (characterized) by an extension of the PQ interval, both in absolute and relative units. 


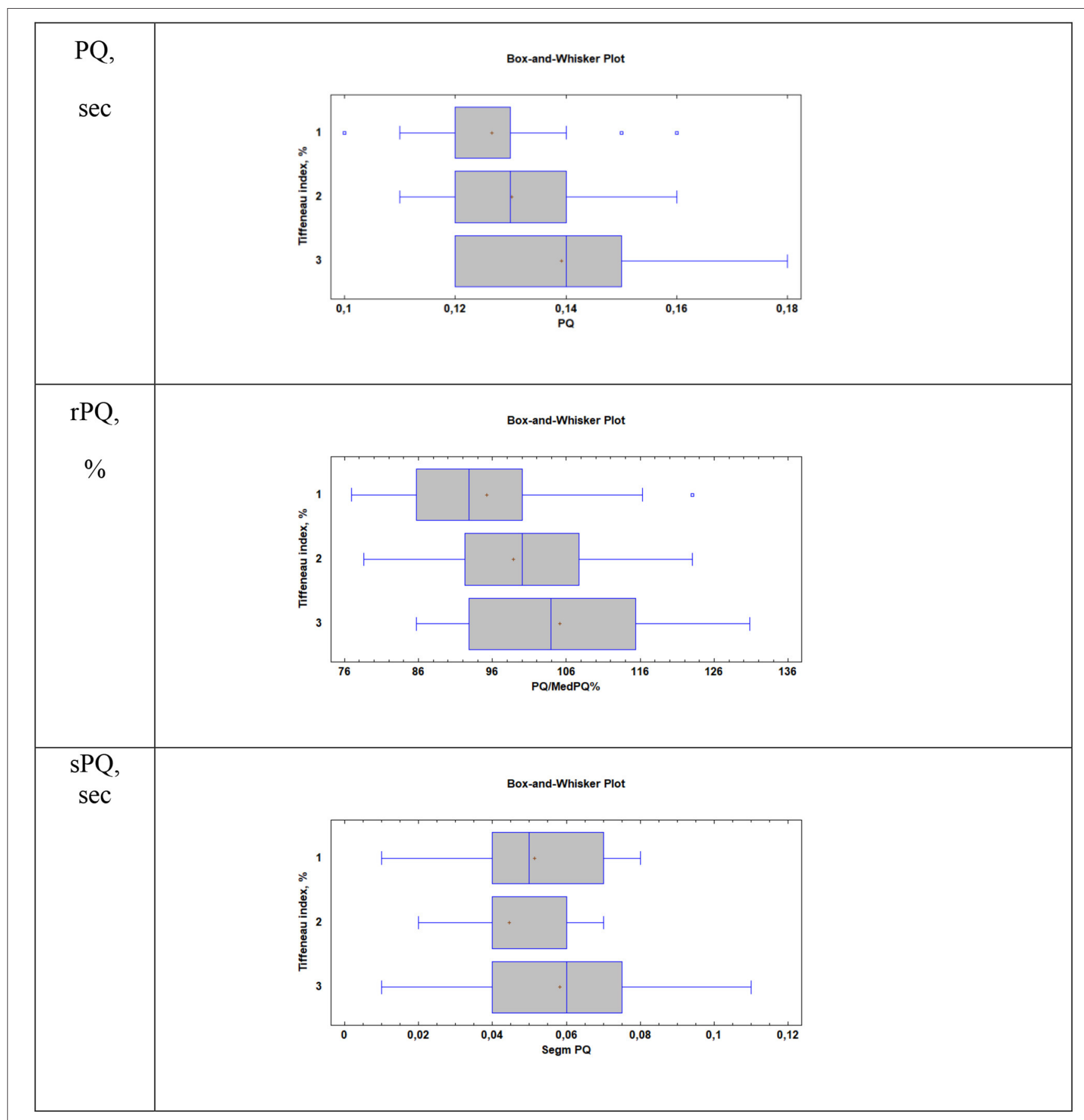

FIGURE 1 | Supraventricular conduction parameters in patients with different values of the Tiffeneau index (R. Tiffeneau) in children with BA. Group 1, Patients with TI $>85 \%$; Group 2, Patients with 75\% < TI <85\%; Group 3, Patients with TI <75\%; PQ, sec-duration of PQ interval; rPQ = PQ/PQ med $\times 100 \%$; sPQ, sec-duration of $P Q$ segment.

\section{DISCUSSION}

This study is aimed at studying the effect of bronchial obstruction on supraventricular conduction in children with BA. Using the method of spirometry and analysis of ECG parameters, it was found that in children with $\mathrm{BA}$, as the Tiffeneau index decreases, there is a statistically significant lengthening of the PQ interval and the sPQ segment, as well as an increase in the rPQ coefficient, which apparently, indicates a slowing of the conduction of impulses from the atria to the ventricles as bronchoconstriction increases. It should be noted that the study did not include children who had a saturation below $98 \%$ during 
TABLE 4 | Relationship between spirometry parameters and ECG atrial component in children with BA.

\begin{tabular}{|c|c|c|c|c|c|c|}
\hline & FVC, I & FEV $_{1}, I$ & $\mathrm{MEF}_{25}, \mathrm{I} / \mathrm{s}$ & $\begin{array}{l}\text { Tiffeneau } \\
\text { index, \% }\end{array}$ & $\begin{array}{l}\text { FEV }_{1}, \\
\% \text { pred }\end{array}$ & $\begin{array}{l}\mathrm{MEF}_{25}, \\
\text { \%pred }\end{array}$ \\
\hline$P, \sec$ & $\begin{aligned} r & =0.20 \\
p & =0.046\end{aligned}$ & $\begin{array}{l}r=0.20 \\
p=0.04\end{array}$ & $\begin{array}{l}r=0.17 \\
p=0.09\end{array}$ & $\begin{array}{l}r=0.02 \\
p=0.82\end{array}$ & $\begin{array}{l}r=0.09 \\
p=0.39\end{array}$ & $\begin{array}{l}r=0.08 \\
p=0.44\end{array}$ \\
\hline$P Q$, sec & $\begin{array}{l}r=0.24 \\
p=0.02\end{array}$ & $\begin{array}{l}r=0.13 \\
p=0.19\end{array}$ & $\begin{array}{c}r=-0.04 \\
p=0.70\end{array}$ & $\begin{array}{c}r=-0.23 \\
p=0.02\end{array}$ & $\begin{array}{c}r=-0.21 \\
p=0.03\end{array}$ & $\begin{array}{c}r=-0.16 \\
p=0.10\end{array}$ \\
\hline$s P Q, s e c$ & $\begin{array}{c}r=0.007 \\
p=0.94\end{array}$ & $\begin{array}{c}r=-0.08 \\
p=0.41\end{array}$ & $\begin{array}{c}r=-0.18 \\
p=0.07\end{array}$ & $\begin{array}{c}r=-0.20 \\
p=0.045\end{array}$ & $\begin{array}{c}r=-0.23 \\
p=0.02\end{array}$ & $\begin{array}{c}r=-0.19 \\
p=0.05\end{array}$ \\
\hline HR, BPM & $\begin{array}{c}r=-0.32 \\
p=0.001\end{array}$ & $\begin{array}{c}r=-0.24 \\
p=0.01\end{array}$ & $\begin{array}{c}r=-0.12 \\
p=0.23\end{array}$ & $\begin{array}{l}r=0.13 \\
p=0.19\end{array}$ & $\begin{array}{l}r=0.09 \\
p=0.37\end{array}$ & $\begin{array}{l}r=0.02 \\
p=0.83\end{array}$ \\
\hline ampP, mm & $\begin{array}{c}r=-0.11 \\
p=0.28\end{array}$ & $\begin{array}{c}r=-0.11 \\
p=0.25\end{array}$ & $\begin{array}{c}r=-0.06 \\
p=0.55\end{array}$ & $\begin{array}{l}r=0.02 \\
p=0.87\end{array}$ & $\begin{array}{c}r=-0.18 \\
p=0.07\end{array}$ & $\begin{array}{c}r=-0.06 \\
p=0.58\end{array}$ \\
\hline$r P Q, \%$ & $\begin{array}{c}r=-0.02 \\
p=0.83\end{array}$ & $\begin{array}{c}r=-0.12 \\
p=0.23\end{array}$ & $\begin{array}{c}r=-0.22 \\
p=0.03\end{array}$ & $\begin{array}{c}r=-0.25 \\
p=0.01\end{array}$ & $\begin{array}{c}r=-0.20 \\
p=0.04\end{array}$ & $\begin{array}{c}r=-0.25 \\
p=0.01\end{array}$ \\
\hline
\end{tabular}

The data is presented as $R(p)$, where $R$ is the correlation coefficient, and $p$ is the level of statistical significance.

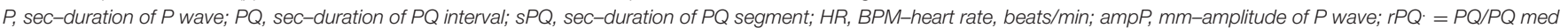

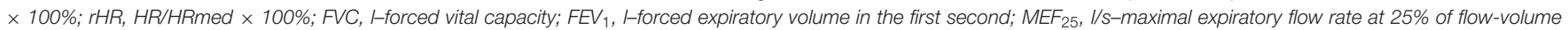
loop; FVC, \% pred-percentage of predicted FVC; FEV 1 , \%pred-percentage of predicted FEV ${ }_{1} ; M_{E} F_{25}$, \% pred-percentage of predicted MEF 25 .

the survey period, which completely excluded the presence of hypoxia in children.

Parameters of the supraventricular component of the ECG (PQ, sPQ segment, rPQ) were statistically significantly higher in patients who had severe manifestations of bronchial obstruction (Tiffeneau index lower than 75\%) compared with children who had no bronchial obstruction or were from mild to moderate (Tiffeneau index higher than 75\%), all $p<0.05$. At the same time, in our study, no differences in the amplitude, shape, and duration of the $\mathrm{P}$ wave in patients with different degrees of severity of bronchoconstriction were observed; the median values of $P$-wave duration in all three groups with different values of the Tiffeneau index were close to $0.08 \mathrm{sec}$, all $p>0.05$. This is consistent with the data of Ghandi et al. (23), in whose study, on comparing patients with BA with healthy children, it was found that the maximum and minimum duration of the $P$-wave were identical in subjects of both groups, although the dispersion of the $P$-wave was higher in patients with asthma. However, this is not entirely consistent with the data of Yucel et al. whose study revealed a tendency to lengthen the maximum duration of the $\mathrm{P}$ wave when analyzed in 12 ECG leads in children with asthma compared to healthy children (35). Thus, the evaluation of the $P$-wave in patients with asthma still requires more detail, with the expansion of the patient group and stratification of patients by age, gender, and severity of bronchoconstriction.

Increased duration of supraventricular conduction (lengthened PQ interval), as well as delayed atrioventricular conduction (lengthened sPQ segment) detected in patients with BA who have spirometric signs of obvious bronchoconstriction, require close attention. The data obtained during the ECG analysis are consistent with the results obtained in a study by Ciftel et al. to assess the impact of the severity of bronchial obstruction on the function of the conduction system of the heart in children with BA. Using the tissue Doppler echocardiography method, the authors found that patients with
BA have a statistically significant increase in interatrial and right atrial conduction times, compared to healthy children (26). Similar patterns of increased right atrial conduction time were observed in patients with COPD, which may be proof that prolonged supraventricular conduction time associated with bronchoconstriction is a universal phenomenon (36). On the other hand, as shown by Daubert et al. prolonged intra-atrial and inter-atrial conduction time are also typical for patients with atrial arrhythmias, including atrial fibrillation (AF) (37).

Thus, it cannot be ruled out that increased supraventricular conduction time in patients with significant bronchoconstriction can be considered as a potential predictor of the formation of subsequent supraventricular arrhythmias, including AF. This is consistent with the results of a study by Shibata et al. showing that respiratory dysfunction in patients with BA is an independent risk factor for AF (38). The mechanism of formation of AF in patients with obstructive pulmonary diseases, however, remains largely unclear. This hinders the development of reliable programs for the prevention of these serious arrhythmias in patients with BA (38).

Distension and dilation of the atria are among the important pathophysiological mechanisms for the formation of supraventricular cardiac arrhythmias. As demonstrated by Schotten et al. (39), this leads to the uneven supraventricular spread of impulses from the sinus node, as well as the formation of re-entrant circuits inside the atrium. Currently, new data have been made available about the oneness of the cardiopulmonary system, including the presence of cardiomyocytes in pulmonary vein tissue, as described in a review by Folmsbee and Gottardi (40). The relationship between certain BA phenotypes and the electromechanical properties of the heart has also been demonstrated. This may, in the future, serve as a starting point for treatment aimed at achieving BA control, being targeted toward corresponding cardiorespiratory mechanisms (40). 
It is also known that the cardiac conduction system is affected by hypoxia, causing pronounced electrophysiological changes in the myocardium (impaired repolarization, decreased electrical activity) (41). Myocardial dystrophy develops, accompanied by reduced cardiac output and impaired acid-base balance, which is a trigger for arrhythmias (42). However, patients who had a saturation below $98 \%$ were not included in this study.

Electrocardiographic changes that accompany an increase in airway obstruction may also be due to autonomic mechanisms. Respiratory homeostasis is known to be controlled by the sympathetic and parasympathetic nervous systems. In BA, there is an increase in the tone of the parasympathetic nervous system, meanwhile the abnormal activity of the parasympathetic nervous system can be closely associated with the pathogenesis of asthma and is reflected in heart rate variability $(43,44)$. Parasympathetic influences slow down the heart rate and prolong PQ. However, our data indicate only PQ lengthening without associated bradycardia. The vagal effect is probably not the only mechanism of delayed conduction of supraventricular impulses.

Taking into account the pilot character of the current study, it is useful to estimate the sample size necessary for validating of the found peculiarities. The sample size $N$ can be crudely estimated using the known formula $N=2 \cdot\left(Z_{\alpha}+Z_{\beta}\right)^{2} /(d / S D)^{2}$, where $Z_{\alpha}$ and $Z_{\beta}$ are the normal distribution values at the levels of type I and II error probabilities of $\alpha / 2$ and $\beta$, respectively; $d / S D$ is the required (clinically-significant) ratio between the group mean value difference $(d)$ and their standard deviations $(S D)$. Using the typical values of $\alpha=0.05$ for $95 \%$ confidence level and $\beta=0.80$ for criterion power level, $Z_{\alpha}$ and $Z_{\beta}$ values are 1.96 and 0.84 , respectively. Considering Group 1 (with normal FEV values) and Groups II+III (with increased FEV values) as two groups with normal and elongated $r P Q$ values, the $d / S D$ value in our study is of about 0.82 . In order to obtain the more significant results with $d / S D=0.2$, the same design study should be conducted in the cohort of 392 patients, and in the cohort of 1,568 patients for $d / S D=0.1(45)$.

\section{CONCLUSION}

In this study, it was found that the duration of the PQ interval and sPQ segment in children with BA who had

\section{REFERENCES}

1. Boulet LP, Reddel HK, Bateman E, Pedersen S, FitzGerald JM, O’Byrne PM. The global initiative for asthma (GINA): 25 years later. Eur Respir J. (2019) 54:1900598. doi: 10.1183/13993003.00598-2019

2. Hogan D, Bernstein JA. GINA updated 2019: Landmark changes recommended for asthma management. Ann Allergy Asthma Immunol. (2019) 124:311-3. doi: 10.1016/j.anai.2019.11.005

3. Global Initiative For Asthma. A Pocket Guide for Health Professionals Updated 2019. (2019). Available online at: https://ginasthma.org/wp-content/uploads/ 2019/04/GINA-2019-main-Pocket-Guide-wms.pdf (accessed August 1, 2020).

4. Licari Brambilla I, Marseglia A, De Filippo M, Paganelli V, Marseglia GL. Difficult vs. severe asthma: definition and limits of pronounced spirometric manifestations of bronchial obstruction, were higher than in patients who had no impaired bronchial patency. The disclosed elongation of the PQ interval and sPQ segment in children with pronounced spirometric markers of bronchial obstruction cannot be ignored, since it is known that in adult patients with $\mathrm{AD}$, the progression of the disease can be accompanied by the formation of supraventricular cardiac arrhythmias, including serious and fatal ones. This study should be repeated with an increased sample size and supplemented by long-term follow-up of patients, including monitoring of spirometric bronchial patency and measurement of ECG parameters.

\section{DATA AVAILABILITY STATEMENT}

All datasets generated for this study are included in the article/supplementary material.

\section{ETHICS STATEMENT}

The studies involving human participants were reviewed and approved by the study was approved by the Ethics Committee of the Privolzhsky Research Medical University, Protocol No. 13 of 10.10.2016. Informed consent was obtained from patients aged 15-17 years, and from the parents of patients under the age of 15 years, in accordance with Federal law No. 323 of 21.11.2011. On the basics of health protection of citizens in the Russian Federation. Written informed consent to participate in this study was provided by the participants' legal guardian/next of kin.

\section{AUTHOR CONTRIBUTIONS}

TE conceived of the study, including design. AG, KAE, AP, and ET were responsible for data collection and data interpretation. $\mathrm{NK}$ and MD-A performed the statistical analysis. All authors read and approved the final manuscript.

\section{FUNDING}

This work was funded by the subsidy of Russian Government Program of Competitive Growth of Kazan Federal University. asthma control in the pediatric population. Front Pediatr. (2018) 6:170. doi: 10.3389/fped.2018.00170

5. Lee LK, Obi E, Paknis B, Kavati A, Chipps B. Asthma control and disease burden in patients with asthma and allergic comorbidities. J Asthma. (2018) 55:208-19. doi: 10.1080/02770903.2017.1316394

6. Eliseeva TI, Balabolkin II. Modern technologies of bronchial asthma control in children (Review). Sovrem Tehnol Med. (2015) 7:168-84. doi: 10.17691/stm2015.7.2.21

7. Kumar P, Singh G, Goyal JP, Khera D, Singh K. Association of common comorbidities with asthma in children: a cross-sectional study. Sudan J Paediatr. (2019) 19:88-92. doi: 10.24911/SJP.106-1544873451

8. Vargas PA. Spreading the word: comorbidity of asthma and depression is not just the product of a vulnerable personality. J Allergy Clin Immunol Pract. (2020) 8:208-9. doi: 10.1016/j.jaip.2019.07.023 
9. Rhee H, Love T, Groth SW, Grape A, Tumiel-Berhalter L, Harrington D. Associations between overweight and obesity and asthma outcomes in urban adolescents. J Asthma. (2019) 1-10. doi: 10.1080/02770903.2019.1633663

10. Heck S, Al-Shobash S, Rapp D, Le DD, Omlor A, Bekhit A, et al. High probability of comorbidities in bronchial asthma in Germany. NPJ Prim Care Respir Med. (2017) 27:28. doi: 10.1038/s41533-017-0026-x

11. Krasilnikova SV, Eliseeva TI, Popov KS, Tush EV, Khaletskaya OV, Ovsyannikov DY, et al. Multimorbidity of upper respiratory tract pathology in children with bronchial asthma. Pediatriya Zhurnal Speranskogo GN. (2018) 97:19-26. doi: 10.24110/0031-403X-2018-97-2-19-26

12. Kercsmar CM, Shipp C. Management/comorbidities of school-aged children with asthma. Immunol Allergy Clin North Am. (2019) 39:191-204. doi: 10.1016/j.iac.2018.12.004

13. Bozkurt Yilmaz HE, Yilmaz M, Sen N, Altin C, Unsal ZE, Tekin A, et al. Assessment of atrial fibrillation and ventricular arrhythmia risk in patients with asthma by P wave/corrected QT interval dispersion. Eur Rev Med Pharmacol Sci. (2018) 22:756-762. doi: 10.26355/eurrev_201802_14308

14. Solov'eva, Sobko EA, Ryazanova NG, Krapohsina AY, Gorgeeva NV, Demko IV. [The relationship between disorders-of external respiration and right heart remodeling in patients with atopic bronchial asthma]. Klin Med. (2015) 93:24-30.

15. Soloveva Sobko EA, Demko IV, Kraposhina AY, Gordeeva NV, Eydemiller NS, Burakov AY. [Early diagnostics and mathematical prediction models remodeling of the heart at patients with atopic bronchial asthma]. Kardiologiia. (2016) 56:64-65. doi: 10.18565/cardio.2016.4.64-65

16. Chicherina EN, Malykh SZ, Shipitsina VV. [The myocardial condition in chronic obstructive pulmonary disease and bronchial asthma]. Klin Med. (2007) 85:23-6.

17. Nedios S, Kircher S, Hindricks G. Cardiovascular magnetic resonance imaging for the detection of left atrial remodeling and the prediction of atrial fibrillation ablation success: More than meets the eye. Int J Cardiol. (2020) 305:161-2. doi: 10.1016/j.ijcard.2020.01.026

18. Warnier MJ, Rutten FH, Kors JA, Lammers JW, de Boer A, Hoes AW, et al. Cardiac arrhythmias in adult patients with asthma. J Asthma. (2012) 49:942-6. doi: 10.3109/02770903.2012.724132

19. Goudis Konstantinidis AK, Ntalas IV, Korantzopoulos P. Electrocardiographic abnormalities and cardiac arrhythmias in chronic obstructive pulmonary disease. Int $J$ Cardiol. (2015) 199:264-73. doi: 10.1016/j.ijcard.2015.06.096

20. Cepelis Brumpton BM, Malmo V, Laugsand LE, Loennechen JP, Ellekjaer H, Langhammer A, et al. Associations of asthma and asthma control with atrial fibrillation risk: results from the nord-trondelag health study (HUNT). JAMA Cardiol. (2018) 3:721-8. doi: 10.1001/jamacardio.2018.1901

21. Chan WL, Yang KP, Chao TF, Huang CC, Huang PH, Chen YC, et al. The association of asthma and atrial fibrillation-a nationwide population-based nested case-control study. Int J Cardiol. (2014) 176:4649. doi: 10.1016/j.ijcard.2014.07.087

22. Tattersall MC, Dasiewicz AS, McClelland RL, Gepner AD, Kalscheur MM, Field ME, et al. Persistent asthma is associated with increased risk for incident atrial fibrillation in the MESA. Circ Arrhythm Electrophysiol. (2020) 13:e007685. doi: 10.1161/CIRCEP.119.007685

23. Ghandi Y, Habibi D, Abasi M. The effect of bronchial asthma on interatrial electromechanical delay coupling obtained using tissue doppler imaging. Iran J Med Sci. (2019) 44:196-203.

24. Adimadhyam S, Schumock GT, Walton S, Joo M, McKell J, Lee TA. Risk of arrhythmias associated with ipratropium bromide in children, adolescents, and young adults with asthma: a nested case-control study. Pharmacotherapy. (2014) 34:315-23. doi: 10.1002/phar.1336

25. Czaja S, Ross ME, Liu W, Fiks AG, Localio R, Wasserman RC, et al. Electronic health record (EHR) based postmarketing surveillance of adverse events associated with pediatric off-label medication use: a case study of shortacting beta-2 agonists and arrhythmias. Pharmacoepidemiol Drug Saf. (2018) 27:815-22. doi: 10.1002/pds.4562

26. Ciftel M, Yilmaz O, Kardelen F, Kahveci H. Assessment of atrial electromechanical delay using tissue Doppler echocardiography in children with asthma. Pediatr Cardiol. (2014) 35:85762. doi: 10.1007/s00246-014-0867-9

27. German M, Kabir MM, Dewland TA, Henrikson CA, Tereshchenko LG. Atrial fibrillation predictors: importance of the electrocardiogram. Ann Noninvasive Electrocardiol. (2016) 21:20-9. doi: 10.1111/anec.12321
28. Mims W. Asthma: definitions and pathophysiology. Int Forum Allergy Rhinol. (2015) 5 (Suppl. 1):S2-6. doi: 10.1002/alr.21609

29. Eliseeva TI, Knyazeva EV, Geppe NA, Balabolkin II. The relationship of spirographic parameters and bronchial responsiveness with asthma control level in children (according to ACQ-5 and ACT-C data). Sovremennye Tehnol Med. (2013) 5:47-52.

30. Sattar Y, Chhabra L. Electrocardiogram. Treasure Island, FL: StatPearls (2020).

31. Ovsyannikov Y, Kuzmenko LG, Nazarova TI, Haled M, Frolov PA, Nguen BV, et al. Clinical and laboratory markers of bacterial infection in children of different ages. Pediatria. (2019) 98:186-92. doi: 10.24110/0031-403X-2019-98-1-186-192

32. Miller MR, Hankinson J, Brusasco V, Burgos F, Casaburi R, Coates A, et al. Standardisation of spirometry. Eur Respir J. (2005) 26:31938. doi: 10.1183/09031936.05.00034805

33. Johnson JD, Theurer WM. A stepwise approach to the interpretation of pulmonary function tests. Am Fam Phys. (2014) 89:359-66.

34. Expert Panel Report 3 (EPR-3). Guidelines for the diagnosis and management of asthma-summary report 2007. J Allergy Clin Immunol. (2007) 120 (5 Suppl):S94-138. doi: 10.1016/j.jaci.2007.09.029

35. Yucel O, Yildiz M, Altinkaynak S, Sayan A. P-wave dispersion and P-wave duration in children with stable asthma bronchiale. Anadolu Kardiyol Derg. (2009) 9:118-22.

36. Caglar M, Dasli T, Turhan Caglar FN, Teber MK, Ugurlucan M, Ozmen G. Evaluation of atrial conduction features with tissue doppler imaging in patients with chronic obstructive pulmonary disease. Clin Res Cardiol. (2012) 101:599-606. doi: 10.1007/s00392-012-0431-7

37. Daubert C, Pavin D, Jauvert G, Mabo P. Intra- and interatrial conduction delay: implications for cardiac pacing. Pacing Clin Electrophysiol. (2004) 27:507-25. doi: 10.1111/j.1540-8159.2004.00473.x

38. Shibata $\mathrm{Y}$, Watanabe $\mathrm{T}$, Osaka $\mathrm{D}, \mathrm{Abe} \mathrm{S}$, Inoue $\mathrm{S}$, Tokairin $\mathrm{Y}$, et al. Impairment of pulmonary function is an independent risk factor for atrial fibrillation: the takahata study. Int J Med Sci. (2011) 8:514-22. doi: 10.7150/ijms.8.514

39. Schotten U, Neuberger HR, Allessie MA. The role of atrial dilatation in the domestication of atrial fibrillation. Prog Biophys Mol Biol. (2003) 82:15162. doi: 10.1016/S0079-6107(03)00012-9

40. Folmsbee SS, Gottardi CJ. Cardiomyocytes of the heart and pulmonary veins: novel contributors to asthma? Am J Respir Cell Mol Biol. (2017) 57:5128. doi: $10.1165 / \mathrm{rcmb} .2016-0261 \mathrm{TR}$

41. Macdonald WA, Hool LC. The effect of acute hypoxia on excitability in the heart and the L-type calcium channel as a therapeutic target. Curr Drug Discov Technol. (2008) 5:302-11. doi: 10.2174/157016308786733546

42. Mallet RT, Manukhina EB, Ruelas SS, Caffrey JL, Downey HF. Cardioprotection by intermittent hypoxia conditioning: evidence, mechanisms, therapeutic potential. Am J Physiol Heart Circ Physiol. (2018) 315:H216-32. doi: 10.1152/ajpheart.00060.2018

43. Liccardi Salzillo A, Calzetta L, Cazzola M, Matera MG, Rogliani P. Can bronchial asthma with an highly prevalent airway (and systemic) vagal tone be considered an independent asthma phenotype? Possible role of anticholinergics. Respir Med. (2016) 117:150-3. doi: 10.1016/j.rmed.2016.05.026

44. Milagro Gil E, Lazaro J, Seppa VP, Malmberg LP, Pelkonen AS, KotaniemiSyrjanen A, et al. Nocturnal heart rate variability spectrum characterization in preschool children with asthmatic symptoms. IEEE J Biomed Health Inform. (2018) 22:1332-40. doi: 10.1109/JBHI.2017.2775059

45. Hulley SB, Cummings SR, Browner WS, Grady DG, Newman TB. Designing Clinical Research: An Epidemiologic Approach, 2nd Edn. Philadelphia, PA: Lippincott, Williams \& Wilkins (2013).

Conflict of Interest: The authors declare that the research was conducted in the absence of any commercial or financial relationships that could be construed as a potential conflict of interest.

Copyright (c) 2020 Gordina, Egoshina, Eliseeva, Vinogradova, Ovsyannikov, Tush, Prakhov, Daniel-Abu, Khaletskaya and Kubysheva. This is an open-access article distributed under the terms of the Creative Commons Attribution License (CC BY). The use, distribution or reproduction in other forums is permitted, provided the original author(s) and the copyright owner(s) are credited and that the original publication in this journal is cited, in accordance with accepted academic practice. No use, distribution or reproduction is permitted which does not comply with these terms. 